\title{
Investigation of the Pt/YSZ interface at low oxygen partial pressure by solid electrochemical mass spectroscopy under high vacuum conditions
}

\author{
Cyril Falgairette $\cdot$ Chun Xia $\cdot$ YongDan Li $\cdot$ \\ Wolfgang Harbich · György Foti $\cdot$ Christos Comninellis
}

Received: 13 April 2010/ Accepted: 4 June 2010/Published online: 6 July 2010

(C) Springer Science+Business Media B.V. 2010

\begin{abstract}
The Pt/YSZ interface was investigated at low oxygen partial pressure under high vacuum (HV) conditions at $400{ }^{\circ} \mathrm{C}$. Two different electrochemical techniques were coupled to mass spectrometric gas analysis using a new solid electrochemical mass spectrometric monitoring device. Under cathodic polarization, the lack of oxygen in the gas phase induces the reduction of the YSZ solid electrolyte which acts as oxygen source for the formation of $\mathrm{O}^{2-}$ ions migrating to the anode. Under anodic polarization, both platinum oxidation and oxygen evolution reaction are identified. $\mathrm{PtO}_{x}$ is formed at both the $\mathrm{Pt} / \mathrm{YSZ}$ and the Pt/gas interface according to two different mechanisms. At the $\mathrm{Pt} / \mathrm{YSZ}$ interface, $\mathrm{PtO}_{x}$ formation is an electrochemical process following a parabolic growth law, while the presence of $\mathrm{PtO}_{x}$ at the $\mathrm{Pt} / \mathrm{gas}$ interface is related to the diffusion of $\mathrm{PtO}_{x}$ formed at the triple phase boundary towards the Pt/gas interface. It is proposed that the side oxygen evolution reaction stabilizes thermodynamically the $\mathrm{PtO}_{x}$ diffusion toward the gas exposed interface during the anodic polarization.
\end{abstract}

C. Falgairette $(\bowtie) \cdot$ C. Xia · G. Foti · C. Comninellis Institute of Chemical Sciences and Engineering, Ecole Polytechnique Fédérale de Lausanne, 1015 Lausanne, Switzerland

e-mail: cyril.falgairette@epfl.ch

C. Xia $\cdot$ W. Harbich

Institute of Condensed Matter Physics, Ecole Polytechnique

Fédérale de Lausanne, 1015 Lausanne, Switzerland

C. Xia $\cdot$ Y. Li

Tianjin Key Laboratory of Applied Catalysis Science and Technology and State Key Laboratory for Chemical Engineering, Tianjin University, School of Chemical Engineering, Tianjin 300072, China
Keywords Solid electrochemical mass spectrometry · SEMS $\cdot$ High vacuum $\cdot \mathrm{Pt} / \mathrm{YSZ} \cdot \mathrm{Pt}$ electrodes . Zirconia oxidation/reduction . Platinum oxidation/reduction · Oxygen storage

\section{Introduction}

Platinum catalyst electrode deposited on yttria-stabilizedzirconia (Pt/YSZ) is one of the most commonly studied systems in the field of solid electrochemistry, which includes gas sensors [1], gas pumps [1], solid oxide fuel cells [2] and electrochemically promoted catalysts [3]. Over the years, numerous applied and fundamental studies have been conducted, mainly at high oxygen partial pressure $(1-100 \mathrm{kPa})$. However, due to the complexity of the system, the electrochemical behavior of Pt/YSZ cells in an oxygen containing atmosphere at high temperature is still not fully understood. In fact, the question of electrochemically induced platinum oxide formation and the mechanism of oxygen chemisorption at the platinum catalyst surface remains a challenging subject of investigation. Due to the low solubility of oxygen in Pt metal, several studies do not consider $\mathrm{PtO}$ formation during anodic polarization. However, recent investigations have shown that, during a prolonged anodic polarization, different oxidized species are formed at different locations in the system, having a major influence on the catalyst properties during and after the polarization step [4-6].

In this paper, we study the electrochemically induced platinum oxidation/reduction mechanism, using a new electrochemical technique (solid electrochemical mass spectroscopy, SEMS) under HV conditions. In this technique, described in detail in a previous paper [7], an 
electrochemical perturbation is imposed to the Pt/YSZ interface. This perturbation can lead to the formation of $\mathrm{O}_{2}(\mathrm{~g})$ which is analyzed online by mass spectrometry. The aim of the experiment is to obtain information on the stability of the YSZ solid electrolyte against cathodic reduction and on the kinetics of the involved redox couples $\left(\mathrm{O}_{2} / \mathrm{O}^{2-}, \mathrm{PtO} / \mathrm{Pt}\right)$.

\section{Experimental}

A commercial YSZ 8\% mol pellet (Technox 802, Dynamic Ceramic) was used as substrate on which platinum electrodes were deposited by magnetron sputtering in $\mathrm{Ar}$ at room temperature. The magnetron operates in the direct current (dc) mode maintaining a discharge of $330 \mathrm{~V}$ at an argon pressure of $1 \mathrm{~Pa}$. Under these conditions, a $1 \mu \mathrm{m}$ thick Pt electrode was deposited with a deposition rate of $0.09 \mathrm{~nm} \mathrm{~s}^{-1}$ on the YSZ pellet, as determined by profilometric measurement (Alphastep, Model 500) of the film deposited on smooth silicon samples processed simultaneously. The size of each Pt electrode (working, counter and reference) is $7 \times 5 \mathrm{~mm}$ giving a geometric surface of $0.35 \mathrm{~cm}^{2}$. The working and counter electrodes were located in a symmetrical face-to-face arrangement on the opposite sides of the YSZ pellet, and the reference electrode lies next to the counter electrode. This geometry ensured a symmetrical current and potential distribution in the cell [8]. Before use, the sample has been treated at $700{ }^{\circ} \mathrm{C}$ in $20 \mathrm{kPa} \mathrm{O} \mathrm{O}_{2}$ during $4 \mathrm{~h}$ in order to stabilize the platinum electrode films [9].

Electrochemical investigations are performed under high vacuum (HV) conditions $\left(10^{-6} \mathrm{~Pa}\right)$ at $400{ }^{\circ} \mathrm{C}$ by solid electrochemical mass spectroscopy (SEMS) using a setup described in detail elsewhere [7]. This new electrochemical technique involves the imposition of an electrochemical perturbation (PGSTAT30, EcoChemie) to the system while monitoring directly by mass spectrometry (QMS, Pfeiffer, Prisma200) the formation of electrochemical products (in the case of this paper $\mathrm{O}_{2(\mathrm{~g})}$ ), released into the gas phase. The operating background $\mathrm{O}_{2}$ partial pressure is $10^{-7} \mathrm{~Pa}$, and $\mathrm{O}_{2}$ (46 purity Carbagas certified) is introduced, if needed, via a UHV leak valve and a capillary stainless steel gas line. The response time of the system is $0.5 \mathrm{~s}$.

In this paper, the SEMS technique is used by applying two different types of electrochemical perturbations with simultaneous MS analysis of the gas phase as follows:

- Perturbation of the Pt/YSZ interface by cyclic voltammetry $(\mathrm{CV})$ with a sweep rate of $v=50 \mathrm{mV} \mathrm{s}^{-1}$ in various potential domains and analysis of the formed $\mathrm{O}_{2(\mathrm{~g})}$ (if any) by MS. This technique is reported as Cyclic voltammetrymass spectroscopy (CV-MS) measurements.
- Perturbation of the Pt/YSZ interface by double step chronopotentiometry (DSCP) for different applied anodic currents and perturbation times, and analysis of the formed $\mathrm{O}_{2(\mathrm{~g})}$ (if any) by MS. The DSCP perturbation includes a pretreatment step (ensuring that the Pt/YSZ interface is in the same initial state before each experiment) and a measurement step. The pretreatment step consists in a constant cathodic current step of $-30 \mu \mathrm{A}$ applied for $10 \mathrm{~s}$. The measurement step consists in a constant anodic current $\left(I_{\mathrm{a}}\right)$ step during a time $t_{\mathrm{h}}$ (charging) followed by a cathodic current $I_{\mathrm{c}}$ (discharging) step. This technique is reported as Double step chronopotentiomentry-mass spectroscopy (DSCPMS) measurements.

All potentials $(E)$ have been reported relative to the $\mathrm{Pt}, \mathrm{O}_{2}\left(p_{\mathrm{O}_{2}}\right)$ reference electrode, where $p_{\mathrm{O}_{2}}$ is the actual oxygen partial pressure. In fact, in this one-compartment set-up, all three electrodes are exposed to the same gas mixture.

\section{Results}

\subsection{Cyclic voltammetry-mass spectroscopy measurements}

Figure 1 shows the effect of the cathodic potential limit, $E_{\mathrm{c}}$, on the CV-MS measurements obtained on the Pt/YSZ interface. In the first potential domain $(-200 \mathrm{mV} / 1000 \mathrm{mV})$, a surface redox couple in the potential region between $100 \mathrm{mV}$ and $600 \mathrm{mV}$ is obtained. The separation between the anodic and

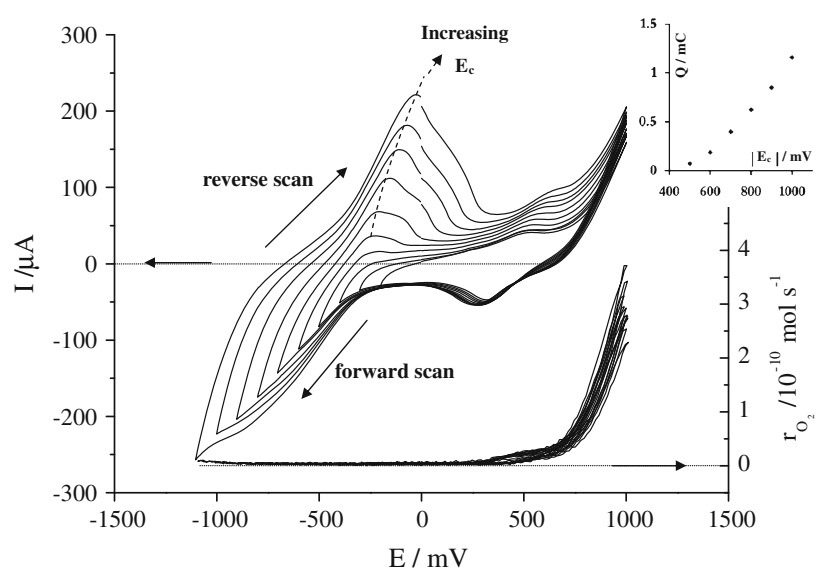

Fig. 1 CV-MS measurements: Effect of cathodic potential limit $E_{\mathrm{c}}$ (from -200 to $-1100 \mathrm{mV}$ by steps of $100 \mathrm{mV}$ ) on cyclic voltammograms of Pt/YSZ interface under HV (left) and corresponding MS results of $\mathrm{O}_{2}$ evolution (right). Inset: Charges estimated by integration of the anodic peak as a function of cathodic potential limit. $E$ is relative to the $\mathrm{Pt}, \mathrm{O}_{2}\left(p_{\mathrm{O}_{2}}\right)$ reference electrode. $T=400{ }^{\circ} \mathrm{C}, p_{\mathrm{O}_{2}}=$ $10^{-7} \mathrm{~Pa}, v=50 \mathrm{mV} \mathrm{s}^{-1}$ 
cathodic peak $\left(\Delta E_{\mathrm{p}}=200 \mathrm{mV}\right)$ indicates that the process is largely irreversible. This surface redox couple is certainly related to the oxidation/reduction of $\mathrm{Pt}$ at the $\mathrm{Pt} / \mathrm{YSZ}$ interface (Eq. 1)

$\mathrm{PtO}_{x(\mathrm{Pt} / \mathrm{YSZ})}+2 x e^{-} \rightleftarrows \mathrm{Pt}+x \mathrm{O}^{2-}$

The MS response shows furthermore that the onset potential of $\mathrm{O}_{2(\mathrm{~g})}$ evolution (Eq. 2)

$2 \mathrm{O}^{2-} \rightarrow \mathrm{O}_{2(\mathrm{~g})}+4 e^{-}$

is about $300 \mathrm{mV}$. This reaction takes places at the triple phase boundaries (TPBs).

As $E_{\mathrm{c}}$ is decreased below $-500 \mathrm{mV}$, the reduction current observed in the $\mathrm{CV}$ during the forward scan decreases strongly down to $-250 \mu \mathrm{A}$ for $E_{\mathrm{c}}=-1100 \mathrm{mV}$. In the reverse scan, an anodic peak is observed which grows and shifts to less negative potentials with decreasing cathodic limit $E_{\mathrm{c}}$. The fact that the involved anodic charge is almost the same as the cathodic charge indicates that during the cathodic polarization an electrical charge is stored at the $\mathrm{Pt} / \mathrm{YSZ}$ interface, certainly due to YSZ reduction (Eq. 3)

$\mathrm{ZrO}_{2}+2 \delta e^{-} \rightleftarrows \mathrm{ZrO}_{2-\delta}+\delta \mathrm{O}^{2-}$

This stored charge is estimated by integration of the involved cathodic (for PtO reduction) or anodic (for $\mathrm{ZrO}_{2-\delta}$ oxidation) charge and found to increase with the cathodic potential limit $E_{\mathrm{c}}$ (insert of Fig. 1). The total amount (more than $1 \mathrm{mC}$ ) indicates that the stored charge is not limited to the Pt/YSZ interface but penetrates several monolayers inside the YSZ solid electrolyte. This penetration can be explained by the electronic conductivity of the reduced YSZ which creates a new interface (YSZ) reduced $/ Y S Z$ allowing electron transfer through the reduced YSZ. As shown from the MS response, no oxygen evolution is involved in this potential domain $(-200$ to $-1100 \mathrm{mV})$. In fact, considering the single chamber configuration of the setup it is suggested that the weak oxygen release observed on the MS results is related to the strong oxygen evolution reaction taking place at the counter electrode.

Figure 2 shows the influence of the upper potential limit, $E_{\mathrm{a}}$, on the CV-MS measurements. The anodic potential limit does not affect the electrochemical behavior of the YSZ solid electrolyte but has a strong effect on the development of the $\mathrm{Pt} / \mathrm{PtO}_{x}$ redox couple. In fact, increasing $E_{\mathrm{a}}$ results in an increase of the involved cathodic charge related to the reduction of $\mathrm{PtO}_{x}$ and in a potential shift to more positive values of the reduction peak. The stored charge related to this reduction process is estimated by integration of the cathodic peak, and is found to increase linearly with the anodic reverse potential (right insert in Fig. 2). The electrochemical process involved in this

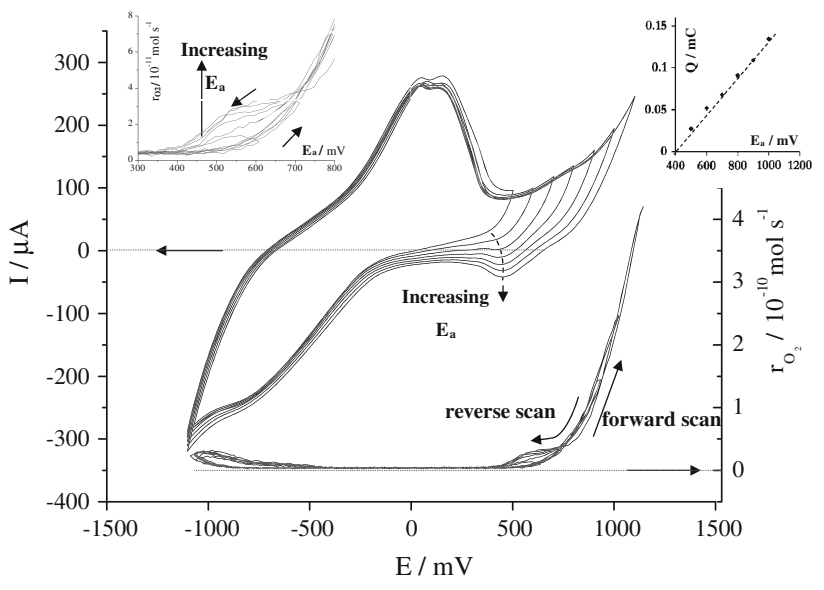

Fig. 2 CV-MS measurements: Effect of anodic potential limit $E_{\text {a }}$ (from 400 to $1000 \mathrm{mV}$ by steps of $100 \mathrm{mV}$ ) on the cyclic voltammogram of $\mathrm{Pt} / \mathrm{YSZ}$ interface under $\mathrm{HV}$ (left) and corresponding MS results of $\mathrm{O}_{2}$ evolution (right). $E$ is relative to the $\mathrm{Pt}, \mathrm{O}_{2}\left(p_{\mathrm{O}_{2}}\right)$ reference electrode. $T=400{ }^{\circ} \mathrm{C}, p_{\mathrm{O}_{2}}=10^{-7} \mathrm{~Pa}, v=50 \mathrm{mV} \mathrm{s}^{-1}$. Right inset: Charges estimated by integration of the cathodic peak as a function of anodic potential limit. Left inset: Magnification of the MS response in the 300 to $800 \mathrm{mV}$ domain

potential domain is attributed to the electrochemical formation/reduction of a $\mathrm{PtO}_{x}$ layer at the $\mathrm{Pt} / \mathrm{YSZ}$ interface, according to reaction 1 .

The total amount of stored charge $(\approx 0.1 \mathrm{mC})$ indicates that in this case the penetration is limited and the stored charge is mainly located at the Pt/YSZ interface under the investigated conditions. As it is shown in the MS response, the rate of oxygen release, $r_{\mathrm{O}_{2}}$, increases as the potential exceeds $300 \mathrm{mV}$. This is attributed to the oxygen evolution reaction (OER) taking place at the triple phase boundaries (TPBs) according to reaction 2 . When the potential is reversed, this reaction slows down and $r_{\mathrm{O}_{2}}$ decreases in a quasi-reversible way down to $700 \mathrm{mV}$ (confirming a response time $<1 \mathrm{~s}$ ) then remains higher than the forward scan forming a plateau between $750 \mathrm{mV}$ and $500 \mathrm{mV}$ $\left(r_{\mathrm{O}_{2}}=30 \times 10^{-12} \mathrm{~mol} \mathrm{Os}^{-1}\right)$ before decreasing to zero at $300 \mathrm{mV}$. This process of oxygen release does not seem to be related to any electrochemical process but rather to desorption of oxygen from the Pt surface according to reaction 4 :

$\mathrm{PtO}_{x} \rightarrow \frac{x}{2} \mathrm{O}_{2(\mathrm{~g})}+\mathrm{Pt}$

Figure 3 shows the influence of the oxygen partial pressure on the YSZ stability (Eq. 3), platinum oxidation/ reduction (Eq. 1) and oxygen evolution (Eq. 2) processes. Notice that the oxygen evolution reaction could not be followed by the MS due to the intrinsic high oxygen partial pressure in these experiments. Hence in this part, only cyclic voltammograms recorded at different $p_{\mathrm{O}_{2}}$ are presented (Fig. 3). One can see that increasing $p_{\mathrm{O}_{2}}$ affects both the 


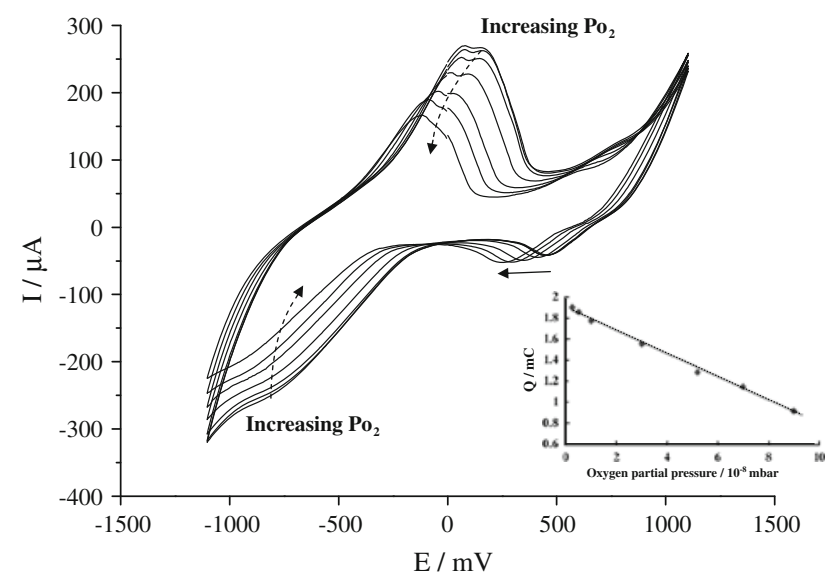

Fig. 3 CV-MS measurements: Effect of $\mathrm{O}_{2}$ partial pressure $\left(p_{\mathrm{O}_{2}}\right)$ on cyclic voltammograms of $\mathrm{Pt} / \mathrm{YSZ}$ interface under $\mathrm{HV} ; p_{\mathrm{O}_{2}}=$ $1 \times 10^{-7} \mathrm{~Pa}, 5 \times 10^{-7} \mathrm{~Pa}, 1 \times 10^{-6} \mathrm{~Pa}, 3 \times 10^{-6} \mathrm{~Pa}, 5 \times 10^{-6} \mathrm{~Pa}$, $7 \times 10^{-6} \mathrm{~Pa}$ and $9 \times 10^{-6} \mathrm{~Pa}$. $E$ is relative to the $\mathrm{Pt}, \mathrm{O}_{2}\left(p_{\mathrm{O}_{2}}\right)$ reference electrode. $T=400{ }^{\circ} \mathrm{C}, v=50 \mathrm{mV} \mathrm{s}{ }^{-1}$. Inset shows the charge estimated by integration of the anodic peak

stability of the YSZ solid electrolyte and the kinetics of the surface $\mathrm{PtO}_{x} / \mathrm{Pt}$ redox couple. In fact, increasing $p_{\mathrm{O}_{2}}$ results in a strong decrease of the stored charge during cathodic polarization at $E_{\mathrm{c}}=-1100 \mathrm{mV}$ indicating an increase of YSZ stability against electrochemical reduction. Furthermore, the cathodic $\mathrm{PtO}_{x}$ reduction peak shifts to less positive values with increasing $p_{\mathrm{O}_{2}}$.

\subsection{Double step chronopotentiomentry-mass spectroscopy measurements}

Figure 4 displays the influence of the anodic current $I_{\mathrm{a}}$ on the chronopotentiometric curves and on the corresponding oxygen evolution monitored by MS (DSCP-MS measurements). The anodic charging step is performed by applying increasing anodic currents from 10 to $100 \mu \mathrm{A}$ in steps of $10 \mu \mathrm{A}$ during $60 \mathrm{~s}$. The current is then reversed to $-30 \mu \mathrm{A}$ (discharging step) until the measured potential reaches its initial value $(-600 \mathrm{mV})$. Four main domains can be distinguished:

- Domain I (from 0 to $10 \mathrm{~s}$ ) where the potential reaches a plateau at about $-400 \mathrm{mV}$. In this domain, strongly shortened with increasing $I_{\mathrm{a}}$, there is no oxygen evolution and the main reaction is the oxidation of reduced YSZ produced during the pretreatment step (reverse of Eq. 3).

- Domain II where the potential increases rapidly from $-400 \mathrm{mV}$ to almost the open circuit potential. In this domain, also shortened with increasing $I_{\mathrm{a}}$, both the $\mathrm{PtO}_{x}$ formation (reverse of Eq. 1) and oxygen evolution (Eq. 2) take place. However, the former reaction seems to predominate.
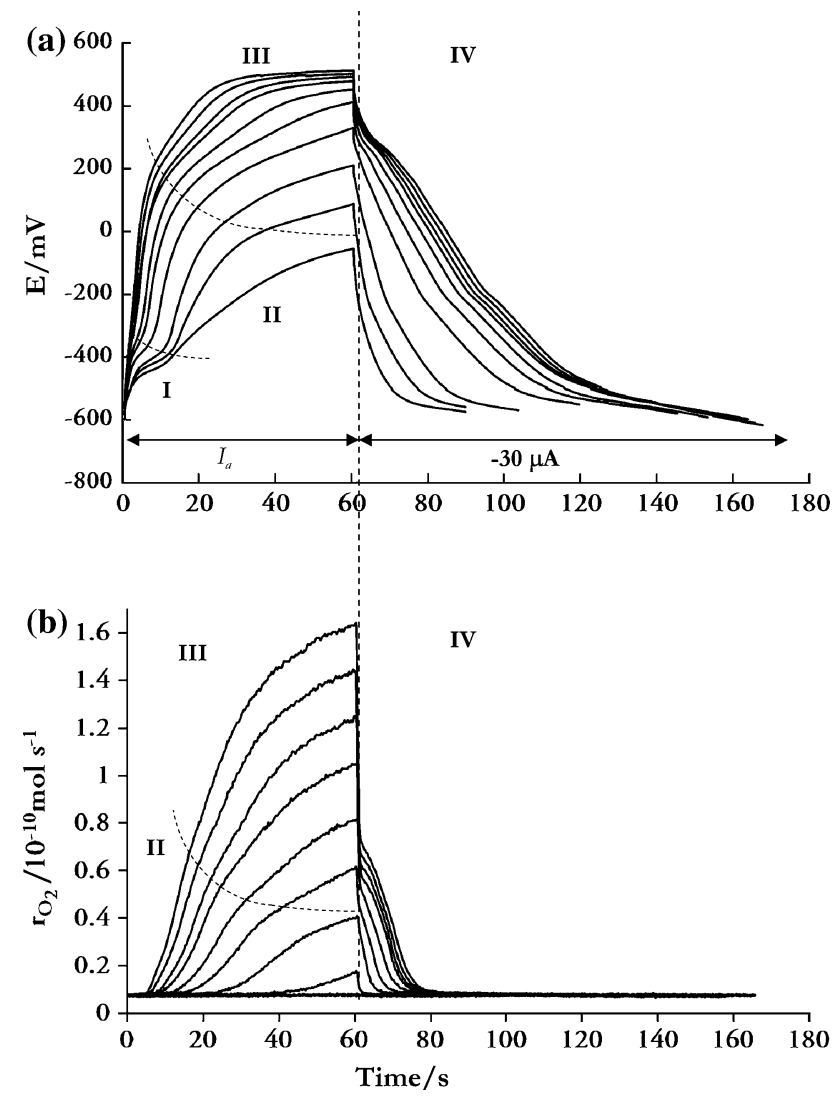

Fig. 4 DSCP-MS measurements : Current-reverse chronopotentiometric transients for anodic polarization with increasing current from 10 to $100 \mu \mathrm{A}$ by steps of $10 \mu \mathrm{A}$; cathodic current is kept at $-30 \mu \mathrm{A}$ (a) and corresponding MS results of $\mathrm{O}_{2}$ evolution (b). $E$ is relative to the Pt, $\mathrm{O}_{2}\left(p_{\mathrm{O}_{2}}\right)$ reference electrode. $T=400{ }^{\circ} \mathrm{C}, p_{\mathrm{O}_{2}}=10^{-7} \mathrm{~Pa}$

- Domain III where the potential increases slowly. In this domain both $\mathrm{PtO}_{x}$ formation and $\mathrm{O}_{2}$ evolution take place, however the $\mathrm{O}_{2}$ evolution (Eq. 2) seems to dominate.

- Domain IV where the potential decreases slowly reaching almost the initial value. In this domain the reduction of $\mathrm{PtO}_{x}$ (Eq. 1) dominates. This domain gets larger with increasing $I_{\mathrm{a}}$, in relation with the increasing amount of formed $\mathrm{PtO}_{x}$ with increasing $I_{\mathrm{a}}$. The release of $\mathrm{O}_{2}$ in this domain (Fig. 4b) under cathodic polarization is very intriguing. This process should involve an oxygen containing species located far from the electroactive Pt/YSZ interface. As suggested in the CV-MS investigation, this may involve desorption of oxygen species lying at the $\mathrm{Pt} / \mathrm{gas}$ interface according to reaction 4. In fact, it is speculated that during the anodic polarization step, the oxygen discharged at the TPB diffuses slowly toward the gas exposed interface.

Figure 5 displays the influence of the anodic holding time $t_{\mathrm{h}}$ on the DSCP-MS measurements. During the charging step, an anodic current of $50 \mu \mathrm{A}$ is applied for 


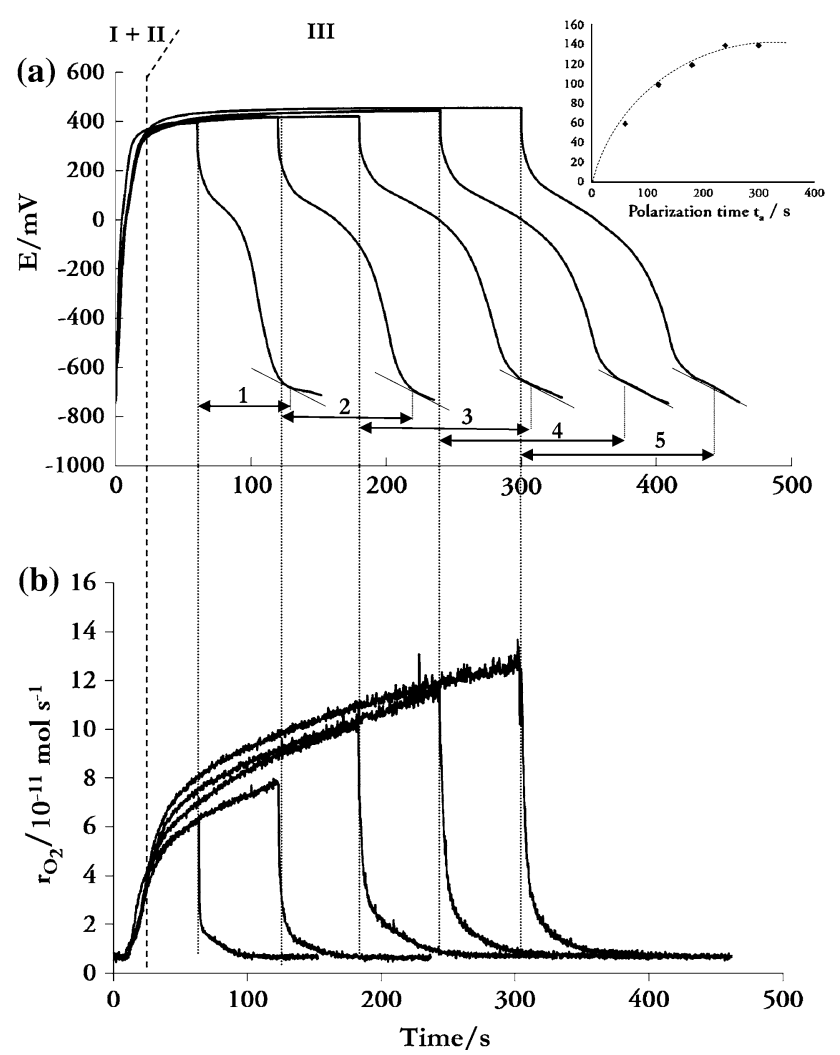

Fig. 5 DSCP-MS measurements : Effect of anodic polarization time on the current-reverse chronopotentiometric transients (a) and corresponding MS results of $\mathrm{O}_{2}$ evolution $(\mathbf{b}), I_{\mathrm{a}}=50 \mu \mathrm{A}, I_{\mathrm{c}}=$ $-50 \mu \mathrm{A}, t_{\mathrm{a}}=60,120,180,240$ and $300 \mathrm{~s}$. $E$ is relative to the Pt, $\mathrm{O}_{2}\left(p_{\mathrm{O}_{2}}\right)$ reference electrode. $T=400{ }^{\circ} \mathrm{C}, p_{\mathrm{O}_{2}}=10^{-7} \mathrm{~Pa}$ Inset: Dependence of $\tau$ on the polarization time

increasing holding time ( 60 to $300 \mathrm{~s}$ by steps of $60 \mathrm{~s}$ ). The current is then reversed to $-50 \mu \mathrm{A}$ until the potential decreases to its initial value of $-700 \mathrm{mV}$ (discharging step). The general feature and interpretation of the results obtained here (Fig. 5a and b) are similar to those reported in Fig. 4. However, on the obtained $E-t$ curves (Fig. 5a) in domain IV, the applied cathodic current induces the reduction of $\mathrm{PtO}_{x}$ (formed in domain $\mathrm{I}$ and II) to metallic platinum. The potential of the electrode returns to its initial value $(E=-700 \mathrm{mV}$ at $t=0 \mathrm{~s})$ due to the decrease of $\mathrm{PtO}_{x}$ surface concentration. The process can be regarded as titration of $\mathrm{PtO}_{x}$ present at the electrode surface at the end of the anodic polarization by the applied cathodic current. The $E-t$ curves observed in the domain IV are similar to those obtained for a potentiometric titration ( $E$ as function of titrant added, $\left.I_{\mathrm{c}} \times t\right)$. When the $\mathrm{PtO}_{x}$ surface concentration drops to zero at the electrode/electrolyte interface, the potential reaches its initial value. In this domain, the time needed for the potential to reach its initial value is reported as the titration time $\tau$. It is related to the surface concentration of $\mathrm{PtO}_{x}$. The variation of $\tau$ with the anodic polarization time is given in the insert of Fig. 5. The titration time, $\tau$, first increases with polarization time, $t_{\mathrm{h}}$, and then saturates at large anodic polarization times (insert in Fig. 5a).

\section{Discussion}

Based on the presented DSCP-MS results, one can define the current efficiencies of the oxygen evolution reaction, $\eta_{\mathrm{O}_{2}}$ (Eq. 5), $\mathrm{PtO}_{x}$ formation at the $\mathrm{Pt} / \mathrm{YSZ}$ interface, $\eta_{\mathrm{PtO}}$ (Eq. 6), and $\mathrm{PtO}_{x}$ formation at the $\mathrm{Pt} /$ gas interface, $\eta_{\mathrm{O}}$ (Eq. 7),

$\eta_{\mathrm{O}_{2}}=\frac{Q_{\mathrm{O}_{2}}}{Q_{\text {Total }}}$

$\eta_{\mathrm{PtO}}=\frac{Q_{\mathrm{PtO}}}{Q_{\mathrm{Total}}}$

$\eta_{\mathrm{O}}=\frac{Q_{\mathrm{O}}}{Q_{\text {Total }}}$

where $Q_{\mathrm{O}_{2}}$ is the equivalent charge of oxygen evolved during the anodic polarization step, determined from the MS results (Figs. $4 \mathrm{~b}$ and $5 \mathrm{~b}$ ), $Q_{\mathrm{PtO}}$ is the equivalent charge of $\mathrm{PtO}_{x}$ reduced electrochemically during the cathodic polarization (Figs. $4 \mathrm{a}$ and $5 \mathrm{a}$ ), $Q_{\mathrm{O}}$ is the equivalent charge of oxygen released during the cathodic polarization determined from the MS results (Figs. $4 \mathrm{~b}$ and $5 \mathrm{~b}$ ) and $Q_{\text {Total }}$ is the total applied anodic charge $\left(I_{\mathrm{a}} \times t_{\mathrm{h}}\right)$.

Figures 6 and 7 show the influence of anodic polarization current, $I_{\mathrm{a}}\left(t_{\mathrm{a}}=60 \mathrm{~s}\right)$ and polarization time $t_{\mathrm{a}}\left(I_{\mathrm{a}}=50 \mu \mathrm{A}\right)$ on $\eta_{\mathrm{O}_{2}}, \eta_{\mathrm{PtO}}$ and $\eta_{\mathrm{O}}$. Increasing $I_{\mathrm{a}}$ and $t_{\mathrm{h}}$ result in a strong decrease of $\eta_{\mathrm{PtO}}$ with a concomitant increase in $\eta_{\mathrm{O}_{2}}$. In fact, the formation of a $\mathrm{PtO}_{x}$ layer at the $\mathrm{Pt} / \mathrm{YSZ}$ double phase boundary appears as a barrier to further oxide growth (autoinhibiting reaction) without affecting the oxygen evolution reaction. Worth to notice that $\eta_{\mathrm{O}}$ increases with the applied

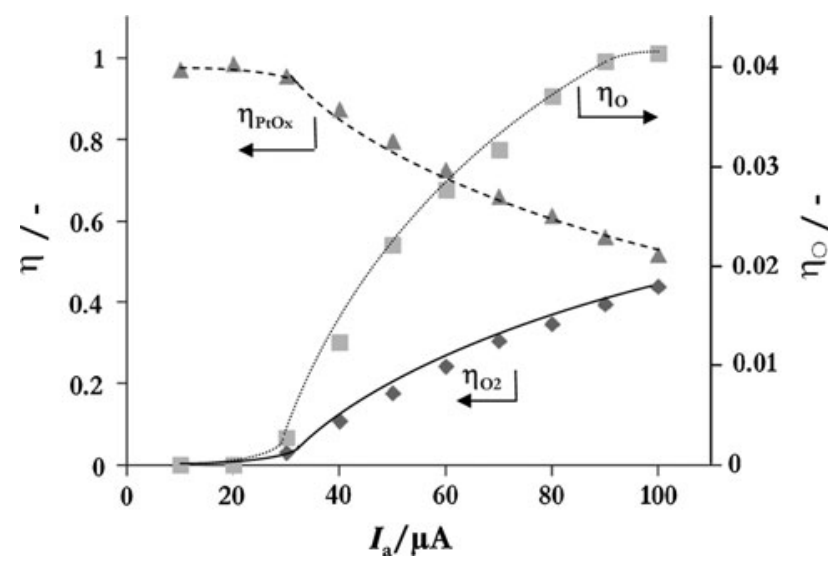

Fig. 6 Effect of anodic polarization current $I_{\mathrm{a}}$ on the current efficiencies $\eta_{\mathrm{O}_{2}}$ (left), $\eta_{\mathrm{PtO}_{x}}$ (left) and $\eta_{\mathrm{O}}$ (right) determined from steady state DSCP-MS experiment of Fig. 4 


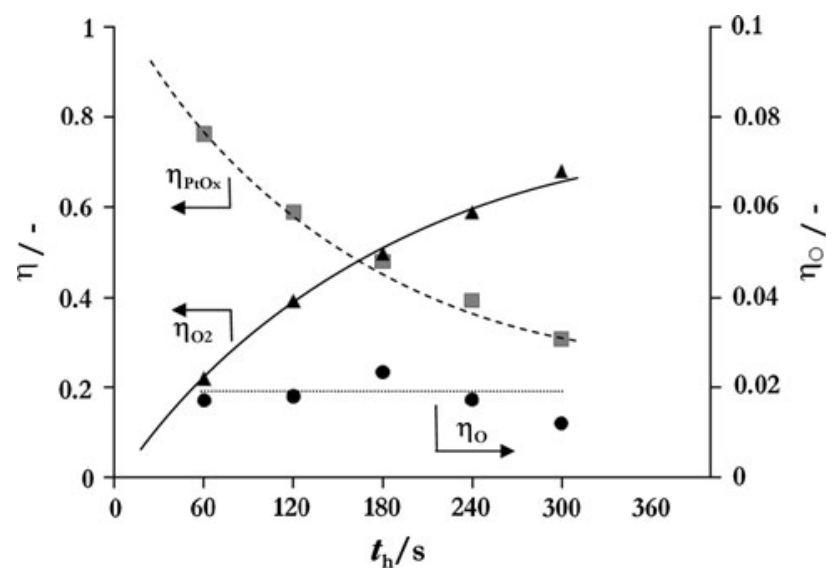

Fig. 7 Effect of holding time $t_{\mathrm{h}}$ of anodic polarization on the current efficiencies $\eta_{\mathrm{O}_{2}}$ (left), $\eta_{\mathrm{PtO}}$ (left) and $\eta_{\mathrm{O}}$ (right) determined from steady state DSCP-MS experiment of Fig. 5

anodic current $I_{\mathrm{a}}$ but remains at a constant value independent of the anodic polarization time. This is an indication that saturation of available adsorption sites on the gas exposed Pt surface is rapidly achieved.

The electrochemical investigation of the Pt/YSZ system, performed in $\mathrm{HV}$ under low oxygen partial pressure at $400{ }^{\circ} \mathrm{C}$ by both CV-MS and DSCP-MS measurements revealed that the $\mathrm{O}^{2-}$ ions present in the solid electrolyte are involved in three main different electrochemical processes upon anodic/cathodic polarization.

\subsection{Zirconia oxidation/reduction (reaction 3)}

Because of the absence of oxygen in the gas phase, upon cathodic polarization, zirconia acts as an oxygen source for the formation of $\mathrm{O}^{2-}$ ions according to Eq. 3. This induces a non-stochiometric, $\delta$, depletion of oxygen in the YSZ solid electrolyte lattice which is known in the literature as YSZ blackening [9-14]. This process is commonly reported to be dependent on the oxygen activity in the solid electrolyte, on the temperature and on the oxygen partial pressure [13].

Worth to notice that upon elapsing cathodic polarization time, the reaction front of zirconia reduction advances toward the inside of the solid electrolyte. In fact, in the vicinity of the cathode, YSZ is suggested to behave as a mixed ionic and electronic conductor allowing the electron supply from the platinum cathode to the reactive sites situated at the YSZ subsurface.

\subsection{Platinum oxidation/reduction (reaction 1) and oxygen evolution (reaction 2)}

Under anodic polarization of the Pt/YSZ interface, two reactions take place in parallel: $\mathrm{PtO}_{x}$ formation (reaction 1) and oxygen evolution (reaction 2). The evolution of the current efficiency for these reactions demonstrates that the platinum oxidation reaction, taking place at the $\mathrm{Pt} / \mathrm{YSZ}$ interface, is rapidly limited by an auto-inhibited oxide growth mechanism (Fig. 7). However, during the anodic polarization, a fraction of the oxygen discharged at the TPBs seems to migrate toward the Pt/gas interface. One should notice that, according to the thermodynamic investigation proposed by Berry [15] and Vayenas [16], under the low oxygen partial pressure applied herein $\left(p_{\mathrm{O}_{2}}=10^{-9}\right.$ mbar), $\mathrm{PtO}_{x}$ is thermodynamically unstable. In fact, at $400{ }^{\circ} \mathrm{C}$ the partial pressure of oxygen should increase up to $1 \mathrm{~Pa}$ in order to stabilize $\mathrm{PtO}_{x}[15,16]$. However, one may assume that the massive release of gaseous oxygen at the TPB induced by the oxygen evolution reaction (reaction 2) creates a huge local increase of $p_{\mathrm{O}_{2}}$ at the platinum gas exposed surface. The species formed at the TPB by $\mathrm{O}^{2-}$ discharge are then proposed to populate the $\mathrm{Pt} / \mathrm{gas}$ interface during the anodic polarization forming $\mathrm{PtO}_{x}$ at the gas exposed interface $\left(\mathrm{PtO}_{x}(\mathrm{Pt} / \mathrm{gas})\right.$ ). This oxide seems to be stable only under conditions of $\mathrm{O}_{2}$ evolution.

Both CV-MS and DSCP-MS measurements revealed an oxygen storage mechanism involving several oxygen storage locations in the Pt/YSZ system as already reported under atmospheric pressure [4-6]. However, in HV conditions at low oxygen pressure, one should consider that YSZ becomes electrochemically active endowing the electrolyte with a mixed ionic electronic conducting character in the vicinity of the cathode.

Initially one can consider that the system is composed of a homogeneous stochiometric YSZ solid electrolyte supporting pure metallic platinum electrodes. Under polarization (Fig. 8), platinum oxidation and oxygen evolution reaction take place at the anode and, because of the lack of gaseous oxygen zirconia is reduced at the cathode.

Cathode : $\quad \mathrm{ZrO}_{2}+2 \delta e^{-} \rightarrow \mathrm{ZrO}_{2-\delta}+\delta \mathrm{O}^{2-}$

Anode : $\mathrm{Pt}+x \mathrm{O}^{2-} \rightarrow \mathrm{PtO}_{x}+2 x e^{-}$

$\mathrm{O}^{2-} \rightarrow \frac{1}{2} \mathrm{O}_{2(\mathrm{~g})}+2 e^{-}$

$\mathrm{PtO}_{(\mathrm{tpb})} \rightarrow \mathrm{PtO}_{(\mathrm{Pt} / \mathrm{gas})}$

At the cathode, the lack of gaseous oxygen induces the reduction of zirconia which acts as oxygen source for $\mathrm{O}^{2-}$ formation and subsequent migration to the anode. Despite this local mixed ionic and electronic conductive character, the bulk of the YSZ solid electrolyte is expected to behave purely as an ionic conductor under the experimental conditions. The $\mathrm{O}^{2-}$ ion supply to the $\mathrm{Pt}$ anode through YSZ is then supposed to be of a constant rate $r=I / 2 F$ during galvanostatic polarization. 


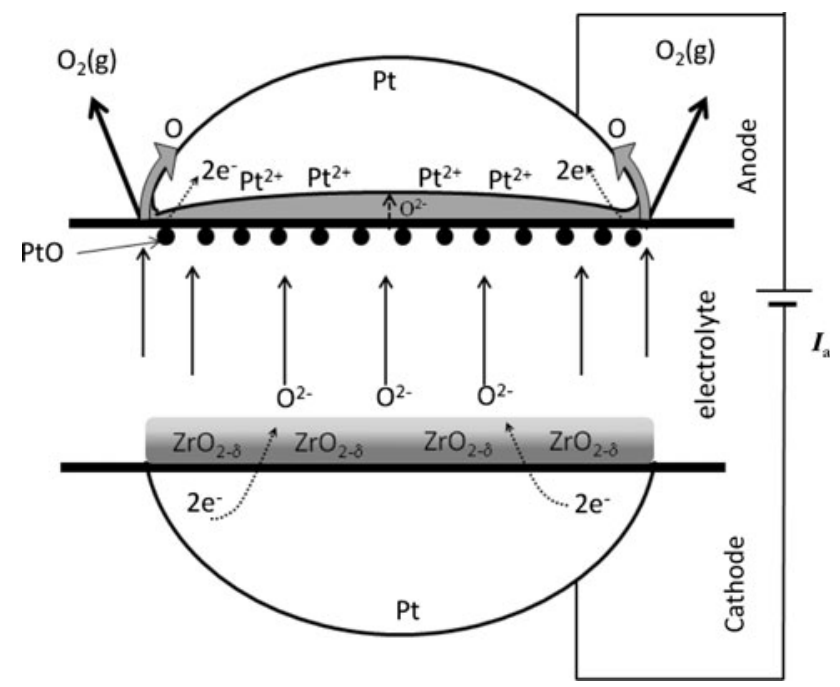

Fig. 8 Schematic representation of the oxidation and reduction processes during anodic polarization of the Pt/YSZ/Pt system under $\mathrm{HV}$. Zirconia is reduced at the cathode, releasing $\mathrm{O}^{2-}$ ions which migrate to the anode across the YSZ electrolyte. At the anode, a thin $\mathrm{PtO}_{x}$ layer is formed at the $\mathrm{Pt} / \mathrm{YSZ}$ interface according to an autoinhibited process. In parallel, at the triple phase boundaries (TPBs), the oxygen reaction takes place leading to a local increase of the oxygen partial pressure which allows the slow diffusion of oxygen discharged at the $\mathrm{Pt} / \mathrm{YSZ}$ interface toward the platinum gas exposed interface

In the first moment of the anodic polarization, the efficiency of $\mathrm{PtO}_{x}$ formation is close to 1 and that of OER is close to zero, and rapidily a monolayer of $\mathrm{PtO}_{x}$ is formed at the $\mathrm{Pt} / \mathrm{YSZ}$ interface. However, this $\mathrm{PtO}_{x}$ formation, which takes place according to a parabolic growth law, is an autoinhibited reaction, and $\eta_{\mathrm{PtO}}$ decreases with elapsing time while $\eta_{\mathrm{O}_{2}}$ increases. In fact, the dominant oxygen evolution reaction is suggested to create a dramatic increase of oxygen partial pressure in the vicinity of the Pt/gas interface. Under such conditions, the formation of $\mathrm{PtO}_{x}$ at the gas exposed interface becomes thermodynamically favored and a fraction of atomic oxygen electrochemically formed at the triple phase boundary slowly migrates toward the $\mathrm{Pt} /$ gas interface forming $\mathrm{PtO}_{x}$ exposed to the gas phase.

\section{Conclusion}

The electrochemical investigation of a sputtered platinum electrode deposited on YSZ polycrystalline substrate was performed under high vacuum conditions $\left(p_{\mathrm{O}_{2}}=10^{-7} \mathrm{~Pa}\right)$ at $400{ }^{\circ} \mathrm{C}$. The coupling of both transient and steady state electrochemical techniques to mass spectrometry (CV-MS and DSCP-MS measurements) allowed to impose a current/ potential perturbation while monitoring online the $\mathrm{O}_{2(\mathrm{~g})}$ formation taking place. The main findings on the electrochemical behavior of Pt/YSZ system revealed by this original approach are:
- Under cathodic polarization, YSZ is reduced in the vicinity of the Pt/YSZ interface acting as an oxygen source for the formation of $\mathrm{O}^{2-}$ ions. This implies YSZ blackening which gives mixed ionic/electronic character to the solid electrolyte. In fact, this allows electron supply from the platinum electrode to the reactive sites involved which are situated at the YSZ subsurface. As a consequence, the reaction front moves forward to the inside of the YSZ solid electrolyte.

- Under anodic polarization, first a $\mathrm{PtO}_{x}$ layer is formed at the $\mathrm{Pt} / \mathrm{YSZ}$ interface according to a parabolic growth law. At a later stage, oxygen evolution reaction (OER) takes place at the triple phase boundary inducing a dramatic increase of oxygen partial pressure in the vicinity of the $\mathrm{Pt} / \mathrm{gas}$ interface. As a consequence, the thermodynamic stability of $\mathrm{PtO}_{x}$ rises up allowing the migration of oxygen, discharged at the TPB, toward the gas exposed Pt surface. Worth to mention that this $\mathrm{PtO}_{x}$ species is decomposed when the OER stops and the initial oxygen partial pressure is restored in the vicinity of the Pt/gas interface.

Acknowledgement Financial support from the Fonds National Suisse de la Recherche Scientifique is gratefully acknowledged.

\section{References}

1. Deportes C (1994) Electrochimie des solides, Presses universitaires de Grenoble

2. Kordesch KV, De Olivera JCT (1989) Ullmann's encyclopedia of industrial chemistry, vol A12. VCH, New York

3. Vayenas CG, Bebelis S, Pliangos C, Brosda S, Tsiplakides D (2001) Electrochemical activation of catalysis: promotion, electrochemical promotion and metal-support interactions. Kluwer Academic/Plenum Publishers, New York

4. Jaccoud A, Falgairette C, Foti G, Comninellis Ch (2007) Electrochim Acta 52:7927

5. Foti G, Jaccoud A, Falgairette C, Comninellis Ch (2009) J Electroceram 23:175

6. Falgairette C, Foti G (2009) Catal Today 146:274

7. Falgairette C, Xia C, Li Y, Harbich W, Comninellis C (2010) J App Electrochem. doi:10.1007/s10800-010-0159-x

8. Eaves J (2003) Thesis no 2883 EPFL (http://library.epfl.ch/ theses/?nr=2883)

9. Jaccoud A (2006) Thesis no 3748, EPFL (http://library.epfl.ch/ theses/?nr=3748)

10. Luerßen B, Janek J, Günther S, Kiskinovac M, Imbihl R (2002) Phys Chem 4:2673

11. Xue J, Dieckmann R (1992) Solid State Ionics 209:53

12. Janek J (2000) Solid State Ionics 131:129

13. Janek J, Korte C (1999) Solid State Ionics 116:181

14. Katsaounis A, Nikopoulou Z, Verykios XE, Vayenas CG (2004) J Catal 222:192

15. Berry RJ (1978) Surf Sci 76:415

16. Vayenas CG, Michaels JN (1982) Surf Sci 120:405 